\title{
REPRESENTAÇÕES SOCIAIS SOBRE A ATUAÇÃO DO PSICÓLOGO ESCOLAR E EDUCACIONAL
}

Leilanir de Sousa Carvalho

Universidade Federal do Piauí - UFPI/CMRV

Ludgleydson Fernandes de Araújo

Universidade Federal do Delta do Parnaíba (UFDPar)

Fauston Negreiros

Universidade Federal do Delta do Parnaíba (UFDPar)
Recebido em: 25/05/2020

$1^{\text {a }}$ revisão em: 12/06/2021

Aceito em: 28/10/2021

\section{RESUMO}

O artigo tem como objetivo investigar as Representações Sociais (RS) da prática do psicólogo escolar e educacional por parte de estudantes universitários de psicologia. A pesquisa foi realizada com 101 universitários do curso de psicologia de uma instituição pública, que estavam cursando ou já havia cursando a disciplina psicologia escolar. Os dados coletados, por meio da Técnica de Associação Livre de Palavras (TALP), foram analisados de acordo com os parâmetros recomendados pela Rede Semântica. As análises foram construídas tendo por base a referência teórica-metodológica da RS e teorias sobre a práticas na Educação. Os resultados apontaram como RS do psicólogo escolar e educacional indicando a importância desse profissional no âmbito escolar, atuando de forma crítica e articulada com a comunidade escolar, e a prática mediante a relevância da atuação.

Palavras-chave: representações sociais; psicologia educacional; psicologia escolar; atuação do psicólogo. 


\section{SOCIAL REPRESENTATIONS ON THE PERFORMANCE OF THE SCHOOL AND EDUCATIONAL PSYCHOLOGIST}

\section{ABSTRACT}

The article aims to investigate the Social Representations (RS) of the School and Educational Psychologist's practice by university students of Psychology. The research was carried out with 101 university students from the Psychology course of a public institution, who were studying or had already studied the School Psychology discipline. The data collected, using the Free Word Association Technique (TALP), were analyzed according to the parameters recommended by the Semantic Network. The analyzes were constructed based on the theoreticalmethodological reference of RS and theories on practices in Education. The results pointed out as SR of the School and Educational Psychologist indicating the importance of this professional in the school environment, acting in a critical and articulated way with the school community, and the practice through the relevance of the performance.

Keywords: social representations; educational psychology; school psychology; psychologist's performance.

\section{REPRESENTACIONES SQCIALES SOBRE EL DESEMPENO DEL PSICOLOGO ESCOLAR Y EDUCATIVO}

\section{RESUMEN}

El artículo tiene como objetivo investigar las Representaciones Sociales (RS) de la práctica del psicólogo escolar y educativo por parte de estudiantes universitarios de psicología. La investigación se realizó con 101 estudiantes universitarios de la carrera de psicología de una institución pública, que estaban cursando o ya habían cursado la disciplina de psicología escolar. Los datos recolectados, utilizando la Técnica de Asociación de Palabras Libres (TALP), fueron analizados según los parámetros recomendados por la Red Semántica. Los análisis se construyeron a partir del referente teórico-metodológico de RS y teorías sobre prácticas en educación. Los resultados señalaron como RS de la psicóloga escolar y educativa indicando la importancia de este profesional en el ámbito escolar, actuando de manera crítica y articulada con la comunidad escolar, y la práctica a través de la relevancia de la actuación.

Palabras Clave: representaciones sociales; psicología educacional; psicología escolar; el desempeño del psicólogo. 


\section{INTRODUÇÃO}

A psicologia é uma profissão na qual se prevalece a presença feminina (Conselho Federal de Psicologia-CFP, 2013), encontra-se em constante crescimento (Heloani, Macêdo \& Cassiolato, 2010). Abrange diversas áreas, entre elas a psicologia escolar e educacional (Souza, 2017).

A atuação do psicólogo na área da educação não é recente, assim seu contexto histórico permeia as práticas no qual seguiam os modelos que enfatizavam o psicodiagnóstico, as práticas das psicoterapias e psicometrias, prezando pelos atendimentos individuais, adaptacionistas e seguindo o modelo de atuação médico (Souza, 2017; Dias, Patias, \& Abaid, 2014; Patto,1990).

Reflexões iniciais sobre a importância de rever a prática do profissional de psicologia na área da educação foram realizadas pela psicóloga Maria Helena Souza Patto, no qual seus estudos apontaram a necessidade da criação de uma forma contextualizada de pensar a psicologia escolar, determinando engajamentos mais significativos na construção de novas práticas a serem desenvolvidas no âmbito educacional (Souza, 2017).

A crítica à atuação do psicólogo escolar e educacional, fortalecida dos anos 90 , fez com que delineassem estudos voltados ao conhecimento do perfil desse profissional, do levantamento das práticas realizadas, da sua localização institucional e regional, e suas visões diante do fenômeno escolares, além da inserção de políticas públicas que conduziram novas reflexões sobre os modelos de atuação (Cruses, 2007).

Nesse sentido, nota-se esforços para a construção de atuações na psicologia escolar próxima a realidade complexa do contexto social (Titon \& Zanella, 2018) O que corrobora com o crescimento de publicações na área da psicologia escolar nos últimos anos que contextualizem as possibilidades de intervenção para psicólogos e os desafios a serem superados (Santos, Morais \& Acioli Neto, 2012).

Assim, o desafio para a atuação do psicólogo no Brasil concentrou-se em atender às demandas de uma sociedade complexa e contraditória, desafiando o psicólogo a buscar novas fontes de formação e a construção de novos modelos de atuação. Para tanto, as mudanças voltadas à educação realizada nos últimos anos e ponderações mais amplas sobre o espaço escolar, pontua-se que o exercício do psicólogo no contexto escolar, se estende para as ações coletivas, institucionais e pedagógicas que interferiam no processo de ensino aprendizagem, não envolvendo apenas o aluno, mas toda a rede que se faz presente no cotidiano escolar (Yamamoto, 2003).

Diante disto, a psicologia escolar vem superando os seus modelos de atuação no âmbito escolar e educacional, esse movimento visa a sua aproximação à escola ou 
instituição educacional de forma coerente com as concepções de homem e de mundo sob uma perspectiva crítica em educação e psicologia (Souza, 2017).

Assim, compreende-se a escola como um espaço em que se estabelecem relações diversas conforme suas funções sociais e escolares e os papéis que cada um ocupa na dinâmica escolar, nesse sentido, a Teoria das Representações Sociais (TRS) colabora com a percepção e o esclarecimento dos conhecimentos coletivos e partilhados pelo grupo, que nem sempre são visíveis ou claros (Sousa et. al., 2004)

Partindo desse pressuposto, questionou-se: quais as RS da prática do psicólogo escolar e educacional por parte de estudantes universitários de psicologia? Nesse sentido, teve-se por base estudos na área da psicologia escolar e educacional ligadas à teoria das RS (Almeida, Santos \& Trindade, 2014; Coutinho, Araújo \& Saraiva, 2013; Santos, Morais \& Acioli Neto, 2012; Sousa \& Villas Bôas, 2011; Menin, \& Shimizu, 2005; Sousa et. al., 2004)

Os estudos colaboram com as múltiplas possibilidades de contribuição dos psicólogos(as) para o sistema de ensino, apontando que profissional encontra-se em contato com diversas temáticas e os diversos atores que perfazem a instituição escolar, contribuindo para os aspectos do desenvolvimento humano, da aprendizagem, dos relacionamentos no ambiente escolar e das mais variadas temáticas de demanda sociais de cada comunidade (Santos, Menezes, Borba, Ramos, \& Costa, 2017). Assim, reflexões e percepções sobre as RS e a psicologia escolar e educacional também são discutidas e pesquisadas, posto que as RS exploram conjuntos de conceitos, afirmações e explicações originadas no decorrer do cotidiano, das comunicações interindividuais e o contexto escolar é composto por diversos grupos que se socializam (Moscovici, 2013).

Desse modo, compreende-se as RS como teorias coletivas sobre realidades, envolvendo assim valores e conceitos que são associadas coletivamente e produzidas em diversos meios sociais, interferindo nos processos formativos de forma individual e coletiva. Essas construções são formadas por meio das interações e comunicações realizadas por grupos por suas percepções cotidianas (Jodelet, 2001; Moscovici, 2003; Coutinho, Araújo \& Saraiva, 2013; Vala, 2018). Na sociedade associam-se aos mitos e sistemas de crenças tradicionais, e podem ser vistas como uma versão contemporânea de senso comum (Almeida, Santos \& Trindade, 2014).

Ao voltar-se para o contexto escolar pode ser entender a TRS sobre o fenômeno que fazem emergir uma identidade grupal a partir das experiências vivenciadas em grupo (Sousa et. al., 2004). As experiências grupais são caracterizadas, segundo Jodelet (2007), pelas representações partilhadas com os outros e que nos servem como apoio, nos guiando por meio da nomeação e definição conjunta sobre os diferentes aspectos do cotidiano.

As opiniões e crenças compartilhadas pelo grupo são favorecidas pelas RS para elaborações teóricas e técnicas de marcadores identitários, podendo organizar e 
regular o espaço social (Deschamps \& Moliner, 2014). Nesse sentido, percebe-se que os elementos estruturadores das RS são influenciados pelos fatores culturais e as particularidades de vida, essa variedade e diversidade contextual fortalecem os conceitos e visões em representação social (Menin \& Shimizu, 2005), nas quais são organizadas e estruturadas por meio de informações, crenças, opiniões e atitudes (Abric, 2003).

Portanto, têm-se as representações como algo concreto e transformador a partir da ação, mesmo com a presença de contradições entre o pensamento e as práticas. São privilegiados os processos sociais em que as representações são formadas e transformadas quando consideradas a reprodução de ideologias por meio das ações e seus mecanismos cognitivos (Moscovici, 2013).

Diante disto, a presente pesquisa teve como objetivo investigar as representações sociais (RS) da prática do psicólogo escolar/educacional por parte de estudantes universitários de psicologia. Essa perspectiva remete a importância de analisar as representações sociais dos universitários em relação à atuação do psicólogo escolar, para que o psicólogo tenha oportunidade de pensar em estratégias de construção e reconstrução de sua prática, refletindo a partir do contexto da formação, verificando a representação dos universitários, que é constituída nas interações com o contexto social e cultural, para assim ser analisado o individual e o social inscrito no papel do psicólogo.

\section{MÉTODO}

\section{TIPO DA INVESTIGAÇÃO}

Trata-se de uma pesquisa exploratória e descritiva de natureza qualitativa e qualitativa, utilizando dados transversais.

\section{LOCAL DA PESQUISA}

A pesquisa foi desenvolvida em uma instituição pública federal, na cidade de Parnaíba-Piauí.

\section{PARTICIPANTES}

Contou-se com 101 universitários de psicologia de uma universidade pública, ambos os sexos, sendo $(68,3 \%)$ feminino e $(31,7 \%)$ masculino, com idades entre 18 e 57 anos, com média de idade de 22,48 anos (DP = 5,43), maioria solteira $(93,1 \%$ ), casados $(5,0 \%)$, outros $(2,0 \%)$, do terceiro ao décimo período, sendo o quarto período com maior número de participantes $(37,6 \%)$. 
Alunos esses, no quais $76,2 \%$ já realizaram estágio em escola durante a graduação e 23,8\% ainda não realizaram o estágio na área escolar (Esta quantidade deveu-se a saturação teórica (Fontanella et. al., 2011).

Utilizaram-se como critério de inclusão os universitários a partir do $3^{\circ}$ período do curso de psicologia e que estivessem em experiência de estágio atualmente ou em período passados, almejando que estes conseguiriam discorrer com propriedade sobre a temática do estudo, visto que teriam embasamento e subsídios teóricos e práticos para relatar aos pesquisadores.

\section{INSTRUMENTOS}

Para contemplar as representações sociais dos participantes, indicou-se os estímulos indutores "educação", "psicologia escolar e educacional", e "atuação do psicólogo escolar", com uso da Técnica de Associação Livre de Palavras (TALP). As palavras estímulos foram elaboradas com base nos objetivos da presente pesquisa e circunda o contexto de como o universitário do curso de psicologia percebe a atuação do psicólogo escolar e educacional por meio das representações sociais dele próprio.

Além destes, dispôs-se de um questionário sociodemográfico construído pelos autores a fim de apreender as características dos participantes (idade, sexo, estado civil, o atual período acadêmico, experiência de estágio na área, conhecimento in loco da atuação do psicólogo escolar e educacional e se acessou esse profissional na instituição em que estuda).

\section{PROCEDIMENTO DE COLETA DE DADOS}

Todos os participantes responderam ao instrumento de forma individual e de maneira coletiva, em salas de aula que foram previamente definidas, por meio do contato e anuência administrativa e dos professores. Foi assegurado aos participantes o anonimato e participação voluntária.

A aplicação foi realizada pelos pesquisadores, iniciando com as instruções para o procedimento de respostas. Ressalta-se que não houve nenhuma recusa em participar da pesquisa.

O tempo de aplicação variou de 25 a 35 minutos. Iniciou-se com a aplicação da técnica de associação livre de palavras (TALP), de modo que eles tinham que relatar cinco palavras de acordo com as palavras estímulo (educação - psicologia escolar e educacional - atuação do psicólogo escolar) e em seguida deviam hierarquizálas de 1 a 5, ou seja, definir a ordem de significação para estes. Em seguida, o questionário sociodemográfico foi aplicado com os participantes, de forma que suas perguntas foram fechadas.

Por fim, após terem sido checados os instrumentos, agradeceu-se a colaboração das turmas pela realização da pesquisa. 


\section{PROCEDIMENTO DE ANÁLISE DOS DADOS}

Após coleta dos dados, os dados da TALP foram analisados de acordo com os parâmetros recomendados pela Rede Semântica (Vera-Noriega, Pimentel, \& Albuquerque, 2005), baseados nos seguintes processos: Peso Semântico (PS), unidade de medida encontrada por meio da soma da ponderação da frequência pela hierarquização assinalada pelos participantes; Núcleo de Rede (NR), composto pelas definidoras com maior peso semântico, utilizando como ponto de quebra o PS a partir do qual a curva adquire seu caráter assintótico e, a Distância Semântica Quantitativa (DSQ), cuja obtenção só é possível a partir das palavras definidoras do NR, atribuindo o valor de $100 \%$ aquela com maior PS, a partir deste valor calculase uma regra de três simples, para se identificar a distância das demais palavras.

Com os dados coletados no questionário sociodemográfico, foi realizado as estatísticas descritivas por meio do software estatístico IBM SPSS 25.

\section{RESULTADOS}

Participaram desta pesquisa 101 universitários do curso de psicologia, cuja maioria é do sexo feminino, com média de idade $22,48(D P=5,43)$, estado civil solteiro, com maior parte os graduandos que cursavam o $4^{\circ}$ período, sendo que a maioria teve experiência de estágio na escola. A maioria (73,3\%) confirmou a existência de um psicólogo escolar e educacional na universidade em que estudam, porém 71,3\% não buscaram o serviço desse profissional, cujo detalhamento encontra-se na tabela 01.

Tabela 01.

Dados sociodemográficos dos estudantes

\begin{tabular}{|c|c|c|c|}
\hline Sexo & Idade & Estado Civil & Períodos \\
\hline Feminino (68.3\%) & \multirow{2}{*}{$\begin{array}{l}\text { Entre } 18 \text { e } 57 \text { anos } \\
\text { Média } 22.48 \text { anos }\end{array}$} & Solteiros $(93,1 \%)$ & $3^{\circ}(16,8 \%)$ \\
\hline \multirow[t]{2}{*}{ Masculino (31.7\%) } & & Casados (5,0\%) & $4^{\circ}(37,6 \%)$ \\
\hline & $(\mathrm{DP}=5.43)$ & Outros $(2,0 \%)$ & $5^{\circ}(6,9 \%)$ \\
\hline Estágio em escolas & $\begin{array}{l}\text { Existe Psicólogo } \\
\text { Escolar e } \\
\text { Educacional na } \\
\text { IES }\end{array}$ & $\begin{array}{c}\text { Acesso ao Psicólogo } \\
\text { Escolar e } \\
\text { Educacional na IES }\end{array}$ & $6^{\circ}(6,9 \%)$ \\
\hline $\operatorname{Sim}(73.3 \%)$ & $\operatorname{Sim}(73,3 \%)$ & $\operatorname{Sim}(28,7 \%)$ & $7^{\circ}(6,9 \%)$ \\
\hline Não (5,0\%) & Não (26,7\%) & Não $(71,3 \%)$ & $8^{\circ}(9,9 \%)$ \\
\hline \multirow[t]{2}{*}{ Outros $(2,0 \%)$} & & & $9^{\circ}(14,9 \%)$ \\
\hline & & & $10^{\circ}(6,8 \%)$ \\
\hline
\end{tabular}

Os resultados obtidos por meio do TALP possibilitaram a análise de campos semânticos acerca de atuação do psicólogo escolar, assim como também possibilitou observar o grau de conhecimento dos participantes sobre a temática, 
fazendo-os não só responder sobre o tema, como refletir a respeito. E os resultados serão discutidos para maior compreensão dos dados coletados.

Tabela 02.

Rede semântica das representações sociais dos universitários sobre o estímulo indutor "Educação"

\begin{tabular}{c|c|c}
$\begin{array}{c}\text { Núcleo da Rede } \\
(\text { NR) }\end{array}$ & Peso Semântico (PS) & $\begin{array}{c}\text { Distância Semântica } \\
\text { Quantitativa (DSQ)\% }\end{array}$ \\
Escola & 100 & $100 \%$ \\
Aprendizagem & 60 & $60 \%$ \\
Professor & 39 & $39 \%$ \\
Família & 20 & $20 \%$ \\
Aluno & 17 & $17 \%$ \\
\hline
\end{tabular}

A análise da Rede Semântica para a palavra "educação" foi definida, prevalentemente, como sendo "escola" (100\%), evidenciado pelo maior peso semântico desta palavra em relação às outras definidoras. Esta é a palavra com maior proximidade, consequentemente, que melhor representa o significado deste sistema, atribuindo-se o mais alto valor: $100 \%$, seguida por: Aprendizagem (60\%), Professor (39\%), Família (20\%) e Aluno (17\%).

Percebe-se (Tabela 2) a proximidade da palavra aprendizagem (60\%). Do ponto de vista semântico, esta palavra é também importante, depois da definidora "escola" (100\%). Estas são as palavras que apresentam a DSQ mais próxima do conceito principal, o que significa dizer que, de acordo com a percepção dos participantes, elas são mais representativas sobre o que se pensa acerca da educação.

Revelaram-se como Núcleo de Rede (RN) e complementam o conceito de educação as palavras: professor, família e aluno. Estas palavras mostram-se consistentes, ao relacionarem-se de forma significativa, como se observa no núcleo da rede de significados. Verificando o NR, na percepção social acerca dos universitários, considerou-se os atores escolares, aqueles que são alcançados pela prática do psicólogo escolar.

A análise da Rede Semântica para a palavra "psicologia escolar e educacional" foi definida, principalmente, como sendo "psicólogo" (100\%). Apresenta-se como a palavra com maior representatividade a essa prática, sendo ela atribuída maior valor, seguida por: Apoio (75\%), Articulação (26,2\%), Escola (22,4\%) e Formação (12,5\%).

Tabela 03.

Rede semântica das representações sociais dos universitários sobre o estímulo indutor "Psicologia escolar e educacional" 


\begin{tabular}{c|c|c}
$\begin{array}{c}\text { Núcleo da Rede } \\
\text { (NR) }\end{array}$ & $\begin{array}{c}\text { Peso Semântico (PS) } \\
\text { Psicólogo }\end{array}$ & $\begin{array}{c}\text { Distância Semântica } \\
\text { Quantitativa (DSQ) \% }\end{array}$ \\
Apoio & 80 & $100 \%$ \\
Articulação & 60 & $75 \%$ \\
Escola & 21 & $26,2 \%$ \\
Formação & 18 & $22,4 \%$ \\
\hline
\end{tabular}

$\mathrm{Na}$ tabela 03, outra categorização chama atenção, em relação à psicologia escolar e educacional, que é "apoio" (75\%). Esta ganha ênfase por estar próxima do ponto de vista semântico, após a palavra definidora, psicólogo (100\%), com maior representação acerca da psicologia escolar e educacional, pois o DSQ está próximo do conceito principal.

Na formação do conceito de psicologia escolar e educacional, também fazem parte do NR as palavras: articulação, escola e formação. Estas se constituem de significados e coerência por se complementarem, como se verifica no núcleo da rede de significados.

Nota-se que os universitários percebem um movimento de criticidade, visto que há o reconhecimento dessa prática e a compreensão dela como participante ativa na área da educação, reconhecendo o espaço de atuação e identificando a formação como fonte e orientação das suas práticas.

A análise da Rede Semântica para a palavra "atuação do psicólogo escolar" foi definida, primeiramente, como sendo "importante" (100\%). Esta palavra apresentou o maior peso semântico em relação às outras definidoras. Portanto, sendo a que melhor representa o significado destes atores sociais, seguido por: Atuação (48,8\%), Crítica (33,3\%), Modalidade (31,1\%) e Desvalorizada (12,2\%).

Tabela 04.

Rede semântica das representações sociais dos universitários sobre o estímulo indutor "Atuação do psicólogo escolar"

\begin{tabular}{c|c|c}
$\begin{array}{c}\text { Núcleo da Rede } \\
\text { (NR) }\end{array}$ & Peso Semântico (PS) & $\begin{array}{c}\text { Distância Semântica } \\
\text { Quantitativa (DSQ) \% }\end{array}$ \\
\hline Importante & 90 & $100 \%$ \\
Atuação & 44 & $48,8 \%$ \\
Crítica & 30 & $33,3 \%$ \\
Modalidades & 28 & $31,1 \%$ \\
Desvalorizada & 11 & $12,2 \%$ \\
\hline
\end{tabular}


Pode-se observar na Tabela 04, que a atuação do psicólogo escolar e educacional é também categorizada como "atuação" (48,8\%). Esta palavra definidora reforça e enfatiza como os universitários enxergam uma possível área, o reconhecimento desses profissionais e potenciais futuros de atuação.

Ainda fazem parte do NR formador do conceito de atuação do psicólogo escolar e educacional as palavras: crítica, modalidades e desvalorizada. Como se observa no núcleo da rede de significados, estas palavras se relacionam e consistem numa concepção dos universitários sobre a atuação do psicólogo escolar.

\section{DISCUSSÕES}

Nesta discussão, buscou-se a interpretação dos sentidos, articulando com os instrumentos utilizados na coleta de dados, agrupando-as para melhor compreendê-las com a execução da TRS. Segundo Moscovici (2013) as RS de determinados grupos sociais, amparadas pelos efeitos da comunicação organizam a realidade e estabelecem as associações que nos ligam uns aos outros.

Na análise da Rede Semântica para a palavra "Educação", os universitários do curso de psicologia, indicam a escola como campo de atuação, além de um local a ser explorado em todos os seus contextos e com todos os atores sociais que compõem o espaço escolar, além de ser um espaço de socialização. Nesse sentido, torna-se relevante refletir sobre a constante mudança da sociedade, que contribuiu para o do surgimento de novos conceitos, teorias e formas de atuar, estimulando a percepção da escola como um todo, além de colaborar e acompanhar tais mudanças, promovendo a qualidade do ensino nas instituições escolares (Damasceno \& Negreiros, 2018).

Pode-se inferir que os atores escolares (professor, família e aluno) foram citados, e apresentam elementos que dão suporte às Representações Sociais dos universitários sobre Educação, ou seja, o que nos revela um olhar contextualizado dos universitários sobre o fenômeno e permeada por teorias e práticas durante o estágio que possibilitaram a reflexão, principalmente, por ter na literatura discussões sobre a influência desse tripé (professor - família - aluno) no ambiente escolar, visto que protagonizam boa parte dos enredos e histórias que permeiam o local, além desses dados revelarem uma formação embasada na psicologia escolar crítica, visto que os universitários utilizaram em seus argumentos pressupostos teóricos pautados em autores de abordagem crítica na área.

Compreende-se que a teoria crítica sobre a psicologia escolar vem se constituindo e crescendo, contribuindo com reflexões diante das questões que indicam novas formas de atuar, assim como repensar métodos defasados e a produção de subjetividade que afeta a qualidade do ensino, com isso a graduação precisa 
pensar em discutir sobre essa construção e as mudanças que vem ocorrendo no contexto educacional (Neves, 2017).

Mediante isso, a graduação deve preparar profissionais que possam visualizar a diversidade de práticas que podem ser desenvolvidas no contexto escolar, além de compreender que sua atuação também tem um papel político, posto que a educação é constituída por políticas públicas que precisam ser conhecidas, avaliadas e discutidas pelos profissionais da área da psicologia, assim contribuindo com a qualidade do ensino e das instituições escolares (Souza, 2010; Oliveira \& Paiva, 2016).

Assim, a importância do professor na produção de um ensino de qualidade tem induzido a elaboração de políticas de formação, como proposta para condução da melhoria do desempenho do aluno (Sousa \& Villas Bôas, 2011).

O exercício de ser professor pode ser definido como uma perspectiva psicossocial, pois compreende o sujeito (professor) como socialmente constituído e construtor de sua realidade, encontrando suporte na teoria das representações sociais, conforme desenvolvida, por Moscovici (1986) e por Jodelet (1989). Não se trata apenas do domínio do professor nas áreas cognitivas, mas requer a compreensão dos processos de identidade profissional, sua subjetividade e das relações desenvolvidas por ele com os outros participantes desse processo de construção da sua identidade (Sousa \& Villas Bôas, 2011).

Nesse sentido, a Família influencia na formação de um sistema de representações que são construídas socialmente e que contribui para a formação do sujeito. A escola, portanto, também se torna responsável nessa constituição de pessoa, mas é cobrada pelo ensino e resolutividade dos problemas que dificultam a aprendizagem, tendo assim de ser dirigida a mesma um posicionamento rumo à resolutividade dos casos (Amaral, Negreiros \& Araújo, 2018).

Discute-se sobre o relato dos próprios professores, num processo de autoculpabilização pelo fracasso escolar dos alunos, prática patologizante alimentada pelos familiares (Damasceno \& Negreiros, 2018). Em contrapartida, é pertinente lembrar que a negligência familiar é apontada como desencadeadora do fracasso escolar, a partir dos conflitos familiares (Patto, 1990). Provocando a reflexão sobre a ênfase dada ao fato de que o aluno é o centro das queixas escolares e fracasso escolar (Patto, 1990; Marinho-Araujo, 2017).

$\mathrm{Na}$ análise da segunda palavra-estímulo, a "psicologia escolar/educacional" foi representada pela palavra "psicólogo", seguido da palavra "apoio". Os dados traduzem concepções da psicologia escolar\educacional condizentes com os arcabouços teóricos.

A base de conhecimento que a psicologia produz é uma fonte na análise da história da relação entre psicologia e educação, evidenciando elementos presentes na forma como são fundamentados os seus estudos e compreensão da realidade, 
assim, ao fazer uma investigação sobre a psicologia escolar e educacional, verificase uma área presente na literatura educacional (Souza, 2017; Martinez, 2009; Patto, 1990).

Percebe-se que também foram evocadas as palavras: articulação, escola e formação. Verifica-se a compreensão a psicologia como participante da rede de apoio da escola.

$\mathrm{Na}$ análise da terceira palavra-estímulo, que se refere à "atuação do psicólogo escolar", os universitários a representam como "importante", que é seguida da palavra "atuação", o que denota o reconhecimento dos participantes sobre o profissional psicólogo escolar e educacional e a forma como vem atuando diante dos processos que ocorrem no âmbito escolar, consequentemente, as mudanças ocorridas no campo da educação e na sociedade promoveram momento de reflexão sobre a prática científico-profissional do psicólogo, proporcionando a transformação. Segundo Martinez (2009) o compromisso com a mudança ocorre por meio da conscientização, tanto na formulação e discussão quanto na atuação do psicólogo visando um trabalho de qualidade na escola.

As palavras: críticas, modalidades e desvalorizada, surgem em meio as inquietações referentes à atuação e valorização do profissional, espera-se que haja um senso crítico em relação ao desempenho de seu trabalho mediante a realidade social dos escolares e da escola, das ferramentas que utilizará e das intervenções a serem realizadas. Nesse sentido, percebe-se que o não reconhecimento da importância desse profissional e dos impactos que pode gerar dentro das escolas levam a não valorização desse profissional (Marinho-Araujo, 2017).

A literatura sobre a atuação do psicólogo escolar e educacional aponta a diversidade de demandas escolares, níveis de ensino e as modalidades em que o profissional pode desempenhar na escola (Santos et. al., 2017; Martinez, 2009). Portanto, a representação é produzida pela interação estabelecida de várias formas e diversas regras sociais (Coutinho, Araújo \& Saraiva, 2013).

Os achados revelam dados coerentes e que serviram de estímulo para a evocação de palavras que construíram a representação que os universitários possuem sobre a atuação do psicólogo escolar. Percebe-se que os participantes estão imersos em uma formação com bases teóricas críticas e suas experiências anteriores com psicólogos escolares trouxeram indicadores que revelam transformações sobre o posicionamento futuro dos universitários em relação à atuação profissional.

Portanto, ao observar o NR, destaca-se o caráter sociopolítico destes atores por meio do resultado de palavras que refletem os discursos atuais sobre a atuação do psicólogo escolar e educacional (Santos et. al., 2017). Novas atribuições apontadas aos psicólogos escolares os colocam como protagonista no processo de transformações no âmbito escolar, mesmo diante de desafios e deficiências no sistema educacional. 


\section{CONSIDERAÇÕES FINAIS}

Os dados coletados revelam, no geral, uma construção social em relação à visão desse grupo, embasada no respaldo da formação. Por outro lado, embora em menor intensidade, também foram verificadas apreensões reflexivas, mediadas pela percepção de que os universitários apresentam quanto a questões sociais e políticas.

Assim, as RS apresentadas indicam a importância desse profissional no âmbito escolar, atuando de forma crítica e articulada com a comunidade escolar, e houve indicativo da desvalorização sofrida pelos profissionais da área, por não haver reconhecimento profissional e poucos profissionais atuando para atender as demandas escolares.

Estas análises e conhecimentos podem ser importantes para subsidiar as ações e atuações futuras da psicologia escolar no sentido de ampliar sua eficácia junto à comunidade escolar, seja pelo aspecto da imagem pública dos psicólogos escolares que pode ser melhorado, seja pelo conhecimento da dinâmica psicossocial envolvida nos processos da área.

As lacunas foram à falta de informação sobre o contato dos universitários com psicólogos escolares durante o período escolar nos níveis fundamental e médio, essa informação auxiliaria na análise sobre suas concepções sobre a atuação do psicólogo escolar.

Como sugestão, poder-se utilizar a rede semântica do conceito em questão para a construção de uma medida para a população específica da comunidade escolar, como: alunos, pais, professores, gestores, dentre outros, de atitudes frente a atuação do psicólogo escolar, utilizando uma escala ou um diferencial semântico. Sugerem-se ainda contemplar profissionais e identificar variáveis que permeiam o conjunto de significados atribuídos a atuação do psicólogo escolar, bem como as transformações no contexto escolar que têm impactado as condições de ensino e aprendizagem. Como também realizar pesquisas comparativas entre universitários que tiveram psicólogos escolares e os que não tiveram psicólogos escolares em suas escolas no período escolar do nível fundamental e médio; e comparar dados entre universitários da rede de ensino privada e pública.

Espera-se que esta pesquisa colabore para a formulação de novos questionamentos acerca da atuação do psicólogo escolar e educacional na realidade brasileira e para o conhecimento científico produzido, desenvolvido e acumulado pela psicologia, permitindo uma compreensão das percepções e dos significados sociais conferidos a esses atores, promovendo repercussões em suas práticas, além de subsidiar direcionamentos mais eficazes. 


\section{REFERÊNCIAS}

Abric, J. C. (2003). A abordagem estrutural das representações sociais: desenvolvimentos recentes. In P. H. F. Campos, \& M. C. da S. Loureiro (Orgs.), Representações sociais e práticas educativas. (pp. 37-58). Goiânia, GO: EDUCG.

Almeida, A. M. de O., Santos, M. de F. de S., \& Trindade, Z. A. (2014). Teoria das representações sociais: 50 anos. Brasília, DF: Technopolitik.

Amaral, E. de B., Negreiros, F., \& Araújo, L. F. de. (2018). Medicalização da educação: representações sociais de professores de Cocal dos Alves-PI. In E. D. de Medeiros, L. F. de Araújo, M. da P. de L. Coutinho, \& L. S. de. Araújo (Orgs.). Representações sociais e práticas psicossociais (pp. 285-298). Curitiba, PR: CRV. Coedição: Teresina, PI: EDUFPI.

Conselho Federal de Psicologia. (2013). Contribuições do Conselho Federal de Psicologia à discussão sobre a formação da(o) psicóloga(o). Brasília: CFP.

Coutinho, M. da P. de L, Araújo, L. F. de., \& Saraiva, E. R. de A. (2013). Revisitando a teoria das representações sociais: uma abordagem teórica. In R. T. da. Cruz, \& E. E. da S. Gusmão (Orgs.) Psicologia: conceitos, técnicas e pesquisas (pp. 9-22). Curitiba, PR: CRV.

Cruses, A. V. V. (2007). Práticas emergentes em psicologia escolar. In A. M. Martinez (Org.), Psicologia escolar e compromisso social: novos discursos, novas práticas (pp. 47-65). São Paulo, SP: Alínea.

Damasceno, M., \& Negreiros, F. (2018). Professores, Fracasso e Sucesso Escolar: Um Estudo no Contexto Educacional Brasileiro. Revista de Psicologia da IMED, 10(1), 73-89. https://doi.org/10.18256/2175-5027.2018.v10i1.2572

Deschamps, J. C., \& Moliner, P. (2014). A identidade em psicologia social: dos processos identitários às representações sociais. $2^{\mathrm{a}}$ ed. Petrópolis, RJ: Vozes.

Dias, A. C. G.; Patias, N. D. \& Abaid, J. L. W. (2014). Psicologia Escolar e possibilidades de atuação do psicólogo: algumas reflexões. Revista Quadrimestral da Associação Brasileira de Psicologia Escolar e Educacional, 18(1). https://doi.org/10.1590/S1413-85572014000100011

Fontanella, B. J. B, Luchesi, B. M., Saidel, M. G. B., Ricas, J., Turato, E. R., \& Melo, D. G. (2011). Amostragem em pesquisas qualitativas: proposta de procedimentos para constatar saturação teórica. Cadernos de Saúde Pública, 27(2), 389-394. https://doi.org/10.1590/S0102-311X2011000200020

Heloani, R., Macêdo, K. B., \& Cassiolato, R. (2010). O exercício da profissão: características gerais da inserção profissional do psicólogo. In Bastos, A. V. B., \& Gondim, S. M. (orgs.). O trabalho do psicólogo no Brasil (pp. 107-130). Porto Alegre, RS: Artmed.

Jodelet, D. (2007). Contribuições das representações sociais para a análise das relações entre educação e trabalho. In L. et al. Pardal (Orgs.), Educação e trabalho: representações, competências e trajectórias. (pp. 11-26). Aveiro: Universidade de Aveiro.

Jodelet, D. (1989). Representations sociales: un domaine en expansion. In D. Jodelet (Org.), Les Représentations sociales. (pp. 31-61). Paris: PUF.

Marinho-Araujo, C. M. (2017). A psicologia escolar nas diretrizes curriculares: espaços criados, desafios instalados. In H. R. Campos (Org.), Formação em Psicologia Escolar: realidades e perspectivas. $2^{a}$ ed. (pp. 11-38). Campinas, SP: Alínea.

Martinez, A. M. (2009). Psicologia Escolar e Educacional: compromissos com a educação brasileira. Psicologia Escolar e Educacional, 13(1), 169-177. https://dx.doi.org/10.1590/S141385572009000100020

Menin, M. S. de S., \& Shimizu, A. de M. (2005). Educação e representação social: tendências de pesquisas na área - período de 2000 a 2003. In M. S. de S. Menin, \& A. de M. Shimizu (Org.) Experiência e representação social: questões teóricas e metodológicas. (pp. 93-130). São Paulo, SP: Casa do Psicólogo.

Moscovici, S. (2013). Representações Sociais: investigações em Psicologia Social. (10ª ed). Petrópolis, RJ: Vozes.

Moscovici, S. (1986). L'Ere des representations sociales. In W. Doise (Org.), L'Étude desrepresentations sociales. (pp. 34-80). Neuchatel-Paris: Delachaux et Niestle.

Neves, M. M. B. J. (2017). Formação inicial em psicologia escolar: questões apontadas por alunos de graduação. In H. R. Campos (Org.), Formação em Psicologia Escolar: realidades e perspectivas. (pp. 39-56). Campinas, SP: Alínea. 
Oliveira, I. F; \& Paiva, I. L (2016). A atuação do psicólogo no campo das políticas sociais: mudanças e permanências. In. D. U. Hur, \& F. Lacerda Júnior, Psicologia, políticas e movimentos sociais (pp. 142-156). Petrópolis, RJ: Editora Vozes.

Patto, M. H. S. (1990). A produção do fracasso escolar. São Paulo, SP: Queiroz.

Santos, D. C. O. dos, Menezes, A. B. de C., Borba, A., Ramos, C. C., \& Costa, T. D. (2017). Mapeamento de competências do psicólogo escolar. Psicologia Escolar e Educacional, 21(2), 225-234. https://dx.doi.org/10.1590/2175-3539201702121109

Santos, M. de F. de S., Morais, E. R. C., \& Acioli Neto, M. de L. (2012). A produção científica em representações sociais: análise de dissertações e teses produzidas em Pernambuco. Revista Psico, 43(2), 200-207. Recuperado de http://revistaseletronicas.pucrs.br/ojs/index.php/revistapsico/article/view/11697/8043

Sousa, C. P. de., \& Villas Bôas, L.P. S. (2011). A Teoria das Representações Sociais e o estudo do trabalho docente: os desafios de uma pesquisa em rede. Revista Diálogo Educacional, 11(33), 271-286. Recuperado de https://www.redalyc.org/html/1891/189119299002/index.html

Sousa, C. P. de. et. al. (2004). Estudo psicossocial da escola. Grupo de pesquisa em Representações Sociais da Pós-graduação em Educação: Psicologia da Educação. Associação Nacional de PósGraduação e Pesquisa em Educação - ANPED. Recuperado de http://www.anped.org.br/biblioteca/item/estudo-psicossocial-da-escola

Souza, M. P. R. de. (2017). Reflexões a respeito da atuação do psicólogo no campo da psicologia escolar/educacional em uma perspectiva crítica. In H. R. Campos, Formação em psicologia escolar: realidades e perspectivas. (pp. 132-142). $2^{\mathrm{a}}$ ed. Campinas, SP: Alínea.

Titon, A. P., \& Zanella, A. V. (2018). Revisão de literatura sobre psicologia escolar na educação profissional, científica e tecnológica. Psicologia Escolar e Educacional, 22(2), 359-368. https://dx.doi.org/10.1590/2175-35392018010922

Vala, J. (2018). Representações sociais e práticas psicossociais. In E. D. Medeiros, L. F. Araújo, M. P. L. Coutinho, \& L. S. L. Araújo (org), Representações sociais e práticas psicossociais (pp. 13-18). Teresina, PI: Edufpi.

Vera-Noriega, J. A., Pimentel, C. E., \& Albuquerque, F. J. B. de. (2005). Redes semânticas: Aspectos teóricos, técnicos, metodológicos y analíticos. Ra-Ximhai, 1, 439-455. Recuperado de https://www.redalyc.org/articulo.oa?id $=46110301$

Yamamoto, O. (2003). Questão social e políticas públicas: revendo o compromisso da psicologia. In A. Bock (Org.), Psicologia e o compromisso social. (pp. 37-54). São Paulo, SP: Cortez.

\section{CONFLITOS DE INTERESSES}

Os autores declaram não existir conflitos de interesses.

\section{SOBRE OS AUTORES}

Leilanir de Sousa Carvalho é Mestre em Psicologia pela Universidade Federal do Piauí - UFPI/CMRV Possui graduação em Psicologia pela Faculdade Integral Diferencial. Especialista em Gestão de Pessoas e Gestalt-Terapia com ênfase em psicoterapia.

E-mail: leilanircarvalho@ymail.com

http://orcid.org/0000-0002-6350-560X

Ludgleydson Fernandes de Araújo é Psicólogo, Doutor em Psicologia pela Universidad de Granada (Espanha) com período sanduíche na Università di Bologna (Itália), Mestre em Psicologia e Saúde pela Universidade de Granada (Espanha), Mestre em Psicologia Social e Especialista em Gerontologia pela UFPB. Professor orientador do Programa de Pós-Graduação (Stricto Sensu) em Psicologia da Universidade Federal do Delta do Parnaíba (UFDPar). Bolsista de Produtividade PQ-2 em pesquisa pelo CNPq.

E-mail: ludgleydson@yahoo.com.br

(2) http://orcid.org/0000-0003-4486-7565

Fauston Negreiros é psicólogo, graduado pela Universidade Estadual do Piauí (2005). Mestre e Doutor em Educação pela Universidade Federal do Ceará (2009;2012). Pós-Doutorando em Psicologia Escolar 
e do Desenvolvimento Humano pela Universidade de São Paulo - USP. É professor-pesquisador associado do Departamento de Psicologia, do Programa de Pós-Graduação (Stricto Sensu) em Psicologia e do Programa de Pós-Graduação (Stricto Sensu) Ciência Política da Universidade Federal do Piauí - UFPI.

E-mail: faustonnegreiros@ufpi.edu.br

http://orcid.org/0000-0003-2046-8463 